\title{
Take Action to Prevent Diabetes - The IMAGE Toolkit for the Prevention of Type 2 Diabetes in Europe
}

Authors
J. Lindström ${ }^{1}$, A. Neumann ${ }^{2,3}$, K. E. Sheppard ${ }^{4}$, A. Gilis-Januszewska ${ }^{5}$, C. J. Greaves ${ }^{4}$, U. Handke ${ }^{6}$, P. Pajunen ${ }^{1}$, S. Puhl ${ }^{7}$, A. Pölönen ${ }^{8}$, A. Rissanen ${ }^{9}$, M. Roden ${ }^{10}$, T. Stemper ${ }^{14}$, V. Telle-Hjellset ${ }^{11}$, J. Tuomilehto ${ }^{12}$, D. Velickiene ${ }^{13}$, P. E. Schwarz ${ }^{2}$, on behalf of the IMAGE Study Group

* IMAGE Study Group: T. Acosta, M. Adler, A. AlKerwi, N. Barengo, R. Barengo, J. M. Boavida, K. Charlesworth, V. Christov, B. Claussen, X. Cos, E. Cosson, S. Deceukelier, V. Dimitrijevic-Sreckovic, P. Djordjevic, P. Evans, A.-M. Felton, M. Fischer, R. Gabriel-Sanchez, A. Gilis-Januszewska, M. Goldfracht, J. L. Gomez, C. J. Greaves, M. Hall, U. Handke, H. Hauner, J. Herbst, N. Hermanns, L. Herrebrugh, C. Huber, U. Hühmer, J. Huttunen, A. Jotic, Z. Kamenov, S. Karadeniz, N. Katsilambros, M. Khalangot, K. Kissimova-Skarbek, D. Köhler, V. Kopp, P. Kronsbein, B. Kulzer, D. Kyne-Grzebalski, K. Lalic, N. Lalic, R. Landgraf, Y. H. Lee-Barkey, S. Liatis, J. Lindström, K. Makrilakis, C. McIntosh, M. McKee, A. C. Mesquita, D. Misina, F. Muylle, A. Neumann, A. C. Paiva, P. Pajunen, B. Paulweber, M. Peltonen, L. Perrenoud, A. Pfeiffer, A. Pölönen, S. Puhl, F. Raposo, T. Reinehr, A. Rissanen, C. Robinson, M. Roden, U. Rothe, T. Saaristo, J. Scholl, P. E. Schwarz, K. E. Sheppard, S. Spiers, T. Stemper, B. Stratmann, J. Szendroedi, Z. Szybinski, T. Tankova, V. Telle-Hjellset, G. Terry, D. Tolks, F. Toti, J. Tuomilehto, A. Undeutsch, C. Valadas, P. Valensi, D. Velickiene, P. Vermunt, R. Weiss, J. Wens, T. Yilmaz

The affiliations are listed at the end of the article
Bibliography

Dol http://dx.doi.org/ 10.1055/s-0029-1240975 Horm Metab Res 2010; 42 (Suppl. 1): S37-S55 @ Georg Thieme Verlag KG Stuttgart. New York · ISSN 0018-5043

\section{Correspondence}

\section{Anne Neumann}

Carl Gustav Carus Medical Faculty, MK III

Technical University of Dresden

Fetscherstr. 74

01307 Dresden

Germany

Phone: + 493514582782

Fax: +493514587319

Anne.Neumann@

uniklinikum-dresden.de

\section{Executive Summary}

When we ask people what they value most, health is usually top of the list. While effective care is available for many chronic diseases, the fact remains that for the patient, the tax payer and the whole of society: Prevention is Better Than Cure.

Diabetes and its complications are a serious threat to the survival and well-being of an increasing number of people. It is predicted that one in ten Europeans aged 20-79 will have developed diabetes by 2030 . Once a disease of old age, diabetes is now common among adults of all ages and is beginning to affect adolescents and even children. Diabetes accounts for up to $18 \%$ of total healthcare expenditure in Europe.

The Good News is That Diabetes is Preventable. Compelling evidence shows that the onset of diabetes can be prevented or delayed greatly in individuals at high risk (people with impaired glucose regulation). Clinical research has shown a reduction in risk of developing diabetes of over $50 \%$ following relatively modest changes in lifestyle that include adopting a healthy diet, increasing physi- cal activity, and maintaining a healthy body weight. These results have since been reproduced in real-world prevention programmes. Even a delay of a few years in the progression to diabetes is expected to reduce diabetes-related complications, such as heart, kidney and eye disease and, consequently, to reduce the cost to society. A comprehensive approach to diabetes prevention should combine population based primary prevention with programmes targeted at those who are at high risk. This approach should take account of the local circumstances and diversity within modern society (e.g. social inequalities) The challenge goes beyond the healthcare system. We need to encourage collaboration across many different sectors: education providers, non-governmental organisations, the food industry, the media, urban planners and politicians all have a very important role to play.

\section{Small Changes in Lifestyle Will Bring Big Changes in Health. \\ Through Joint Efforts, More People Will \\ be Reached.}

The Time to Act is Now.

\begin{tabular}{ll}
\hline Abbreviations \\
DPS: & Finnish Diabetes Prevention Study \\
FINDRISC: & Finnish Diabetes Risk Score \\
IFG: & Impaired fasting glucose \\
IGT: & Impaired glucose tolerance \\
OGTT: & Oral glucose tolerance test \\
T2DM: & Type 2 diabetes mellitus
\end{tabular}

\section{Why is it Time to Act? \\ $\nabla$}

The alarming epidemic

- In Europe, around 55 million adults have diabetes.

- By 2030, this figure is estimated to rise to 66 million adults. 
- The highest increase in incidence is in the 30-40 year old age group. This has, and will continue to have, a strong impact on national economies due to loss of productivity.

\section{Risk factors: Obesity, unhealthy diet, and sedentary lifestyle}

Diabetes develops as a result of an interaction between genes and lifestyle. Obesity is an important risk factor for diabetes. More than half of European adults can be classified as overweight or obese. Genetically, most of us are inadequately adapted to the modern lifestyle with its constant supply of energy-dense food and beverages and a minimal requirement for physical activity.

\section{What causes diabetes?}

Diabetes is caused by the inability of the body's cells to respond to insulin, which results in lower uptake of glucose from the blood by body tissues ("insulin resistance"). To compensate, the pancreas produces and secretes more insulin to clear blood glucose from the circulation. Over time, the pancreas becomes exhausted and is unable to produce sufficient insulin to keep up with the demands of the body. This leads to elevated blood glucose (hyperglycaemia) and finally to the development of diabetes.

\section{Large number of unknown cases}

The progression to diabetes generally takes many years and is mostly asymptomatic. This means that the number of people not knowing that they have diabetes is very high. Studies estimate that for every one or two diagnosed cases of diabetes there is one undetected case.

\section{Complications through late diagnosis}

Diabetes is a severe disease. If it is not diagnosed and treated properly it can lead to serious and costly complications such as cardiovascular disease, diabetic neuropathy, diabetic foot syndrome with amputations, renal failure and blindness. Hyperglycaemia (even prior to diabetes) also increases cardiovascular risk and exacerbates periodontal infection (gum disease).

\section{Costs for the healthcare system and society}

The longer the duration of the disease, the more likely it is that there will be costly complications. In European countries, diabetes accounts for up to $18 \%$ of total healthcare spending. With an ageing population, these costs are likely to increase if the epidemic cannot be reversed. Furthermore, the costs to society through lost productivity may be as much as five times the direct healthcare costs. Additionally, diabetes has a major impact on the quality of life of the patients and his/her family.

\section{Prevention is possible: Evidence from international studies}

Evidence from large trials from Finland, Sweden, the USA, China, India, and Japan has proven that lifestyle interventions can halt, or at least delay, the onset of diabetes in people who are identified as having high risk. The key to prevention is lifestyle changes such as weight reduction (if participants were overweight), increased physical activity, dietary modifications to increase dietary fibre and reduce total and saturated fat intake. The more of these goals the participants achieved, the lower was their risk of developing diabetes ( $\bullet$ Fig. 1).

These findings from clinical studies have been successfully replicated in "real-world" prevention programmes in health-care settings in many European countries.

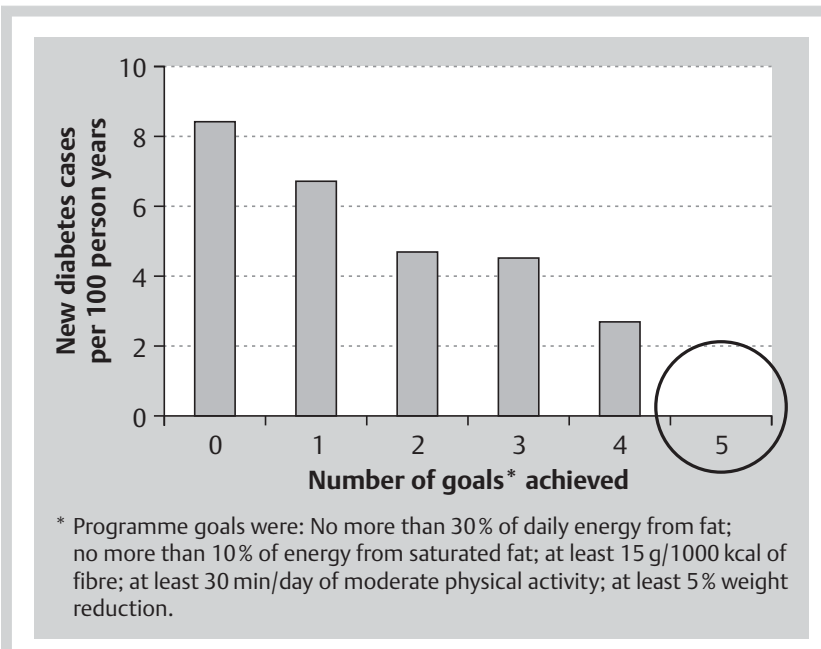

Fig. 1 Achieving all five of the lifestyle goals* prevented diabetes for at least 7 years in the Finnish Diabetes Prevention Study (DPS). Modified from: Lindström et al. [11].

Economic and social benefits of diabetes prevention The cost effectiveness of lifestyle interventions has been documented in a number of clinical trials.

The costs of preventive interventions must be compared with the substantial annual cost per year of treating diabetes and its complications.

\section{How Can I Make a Difference? \\ $\nabla$}

Prevention as a collaborative effort -

key partners to engage

Diabetes is not only an individual health problem, but also a public health problem. The increasing prevalence of diabetes has its origins in cultural changes and policies that lie far outside the health sector. Thus, the responsibility for preventive efforts does not depend only on the healthcare system. An effective and sustainable prevention strategy requires action at both the individual and the societal level. Therefore a wide range of partners have to be involved in both approaches ( $\bullet$ Fig. 2 ).

\section{Why and how to involve societal partners}

Effective diabetes prevention for individuals needs to be embedded into a supportive social environment. Therefore all societal partners should aim to create a less obesogenic/diabetogenic environment to facilitate lifestyle changes and sustainability of changes. The promotion of healthy food and physical activity should ideally become part of an "media campaign" including schools, universities, communities, work environment, etc. with the aim of attracting people to choose them because of their health enhancing effects.

\section{Practical tips for societal support}

- Contact work place communities to support health promotion

- Contact the restaurants and cafeterias in your area and suggest menu labelling (fat, fibre and energy content), healthy options and campaigns 
Local and national media

Providing continuous, comprehensive and reliable information on healthy lifestyle issues

\section{Local and national authorities}

Responsible for long-term strategy planning, sustainability and quality management of the preventive efforts

\section{Individual level}

Target group: persons at risk for T2DM

Goal: Promote lifestyle changes to reduce diabetes risk and improve health

Involved players:

Multidisciplinary team of

- doctors, dentists, nurses

- public health experts

- registered dieticians

- exercise specialists

\section{Other relevant prevention} programmes

As the measure for preventing or delaying type 2 diabetes are

effective in management of obesity

(and its comorbidities) as well as

the effects of premature

atherosclerosis leading to cardiovascular diseases, there

should be a procedure to network with other relevant prevention programmes and public educational activities

\section{Societal level}

Target group: whole population

Goal: Integration of less obesogenic/ diabetogenic/sedentary environment

Involved players:

- local decision makers/ city planners

- kindergartens and schools

- communities industries

- sports clubs facilities

- patient associations

- health insurance companies

Political level: health in ALL policies, following a national action plan for prevention with focus on

a) Advocacy

b) Community support

c) Fiscal and legislative changes involving infrastructure

d) Engagement of privte sector (e.g. health at workplace and ensuring healthy policies in food industry)

Fig. 2 Diabetes prevention as a collaborative effort.

- Cooperate with kindergartens, schools, universities and adult education centres offering programmes for healthy eating and physical activity

- Contact local sports clubs and suggest promotions for special groups and discounts for high-risk clients

- Collaborate with non-governmental organisations (e.g. patient associations)

- Ask local and national authorities or decision makers (e.g. politicians) for support in health promotion

- Involve insurance/health insurance companies

- Get the local and national media interested, for example by engaging prominent people as "ambassadors" for promoting healthy lifestyle or by initiating a contest (e.g. "The healthiest company", "The healthiest class", "The healthiest city district")

- Make use of communication channels (e.g. audio, video, mobile services, social media)

- Establish a website resource promoting healthy lifestyle

\section{How to build a multidisciplinary prevention team}

Diabetes prevention requires the involvement of several professional disciplines, including medicine, behaviour change, nutrition, and physical activity. To build a strong prevention team and network of professionals, aim to engage experts from these various backgrounds who have an interest in and enthusiasm for diabetes prevention. Remember that any prevention programme needs to be mindful of, and sensitive to, cultural and ethnic differences.

\section{Practical tips for networking}

- Assess your capabilities (what are your skills, are they up-todate?)

- Find out about relevant existing projects; identify potential for collaboration (e.g. projects focusing on prevention of obesity, cardiovascular diseases, respiratory diseases, degenerative joint problems, depression)

- Involve the people who are in charge of allocating healthcare resources in your district/centre

- Establish networks or "quality circles" of people who are active in prevention, so that you can exchange experiences and learn from each other

- Increase your advocacy and marketing skills

\section{How to Budget and Finance a Prevention Programme $\nabla$}

The cost per person for diabetes prevention interventions varies substantially between countries and depending on the setting, the mode, and intensity of intervention offered. 
Make a realistic budget (see the Appendix)

Take into consideration:

- Administrative costs

- Salary costs

- Travel costs

- Laboratory costs

- Costs for the intervention

$\checkmark$ Premises

Materials

Possible sources of income:

- Alternative public funding, e.g. charity funding or stipends

- Contributions from collaborating partners

- Private funding, legacies, health insurance companies

- Participation fees

- Contributions from participants in seminars

- Charitable and research bodies

The number of clients who can be treated by a full-time prevention team depends on various factors (budget, setting, number of contacts, etc.).

\section{How to Identify People at Risk}

$\nabla$

\section{Diabetes risk factors}

Modifiable risk factors are linked to higher diabetes risk. These are the factors where you should aim to support change to prevent diabetes. Most important are:

- Overweight and obesity

- Increased risk: body mass index (BMI) 25-30 or waist circumference $80-88 \mathrm{~cm}$ (women) or 94-102 cm (men)

- High risk: $\mathrm{BMI}>30$ or waist circumference $>88 \mathrm{~cm}$ (women) or $>102 \mathrm{~cm}$ (men)

For other ethnic groups than Europids cut-off points are lower, (see Alberti et al. [1] for these)

- Low physical activity (see chapter "Physical activity to prevent diabetes")

- Unhealthy diet (see chapter "Nutrition and dietary guidance to prevent diabetes")

- Hyperglycaemia: Over $30 \%$ of people with hyperglycaemia will develop diabetes within the next 5 years; over 10 times the risk of an average person

- Impaired fasting glucose IFG: fasting plasma glucose 6.1$6.9 \mathrm{mmol} / \mathrm{l}(110-125 \mathrm{mg} / \mathrm{dl})$

- Impaired glucose tolerance IGT: plasma glucose 2 hours after $75 \mathrm{~g}$ glucose load $7.8-11.0 \mathrm{mmol} / \mathrm{l}(140-199 \mathrm{mg} / \mathrm{dl})$ in an oral glucose tolerance test (OGTT)

- Hypertension and lipid disorders: these indicators of the metabolic syndrome often correspond with hyperglycaemia

- Depression: may be associated with physical inactivity and an unbalanced diet

Non-modifiable risk factors are useful in the identification of individuals who would benefit from making lifestyle changes. Most important are:

- Age: risk increases with increasing age; recommended age limit for risk assessment is $>40$ years

- Family history of diabetes: a marker of genetic predisposition

- Ethnicity: people originating from South East Asia, Japan, China have higher risk

- Women with gestational diabetes or babies weighing $>4 \mathrm{~kg}$ at birth - an indication that a woman is susceptible to glycaemic disorders
- History of cardiovascular disease: a marker of disturbed metabolism

- Low birth weight: being born small for gestational age predisposes to diabetes

Environmental risk factors contribute to lifestyle. Ideally, environmental conditions should make a health-promoting lifestyle an easy, attractive and affordable choice for everyone (population approach). Environmental risk factors include:

- Environment promoting inactivity: e.g. lack of bike lanes, play grounds, sport facilities

- Environment promoting unhealthy diet: e.g. lack of supermarkets or work place cafeterias with healthy and affordable food and drink options

- Low socioeconomic status

- Cultural and religious constraints

- Stress \& distress: e.g. unemployment, partnership problems, multi-morbidity, social isolation of the elderly

\section{Risk assessment}

A lifestyle programme aiming at increased physical activity and dietary modification could be beneficial for a wide range of people. However, as resources are normally limited, intensive programmes should be targeted at individuals at increased risk of developing diabetes (high-risk approach) ( $\bullet$ Fig.3). To identify adults at high risk several approaches can be used. Please note that there are no absolute threshold values for risk and therefore inclusion criteria should be based on the combination of risk factors and the resources available.

Several risk scoring algorithms have been developed for estimating diabetes risk (see Appendix). The Finnish Diabetes Risk Score FINDRISC (see Appendix) is one example. It is a low-level, fast, simple and non-invasive questionnaire that gives an estimate of individual's risk of getting diabetes in the next 10 years. It can be filled in by the person himself/herself and also serves as a "miniintervention" as it gives information about diabetes risk factors in a simple and easy-to-understand way. If the score value is high ( $>14)$ a blood test is recommended to detect possible diabetes (OGTT being the "gold standard" test).

Computer searches of existing databases, for example General Practitioner's patient records can be used to identify high-risk individuals. The search algorithm can include available parameters like age, BMI, fasting blood glucose, blood pressure, and family history of diabetes (see Appendix).

Hyperglycaemia can be diagnosed by measuring blood glucose either in the fasting state $(\rightarrow \mathrm{IFG})$ or after an oral glucose load $(\rightarrow$ IGT). Some high-risk individuals may have previously undiagnosed diabetes (i.e. fasting glucose $\geq 7.0 \mathrm{mmol} / \mathrm{l}(126 \mathrm{mg} / \mathrm{dl}$ ) or 2h glucose $\geq 11.1 \mathrm{mmol} / \mathrm{l}(200 \mathrm{mg} / \mathrm{dl})$ or HbA1c $\geq 6.5)$ and should be referred on for appropriate treatment.

Many of the people you try to reach will see no need to take action since subjectively they feel healthy and do not understand the implications of being at high-risk for diabetes. Often ethnic minorities/immigrants and people with low socio-economic status have a high-risk profile. There may be additional challenges in engaging and delivering services to these populations (see Appendix). 


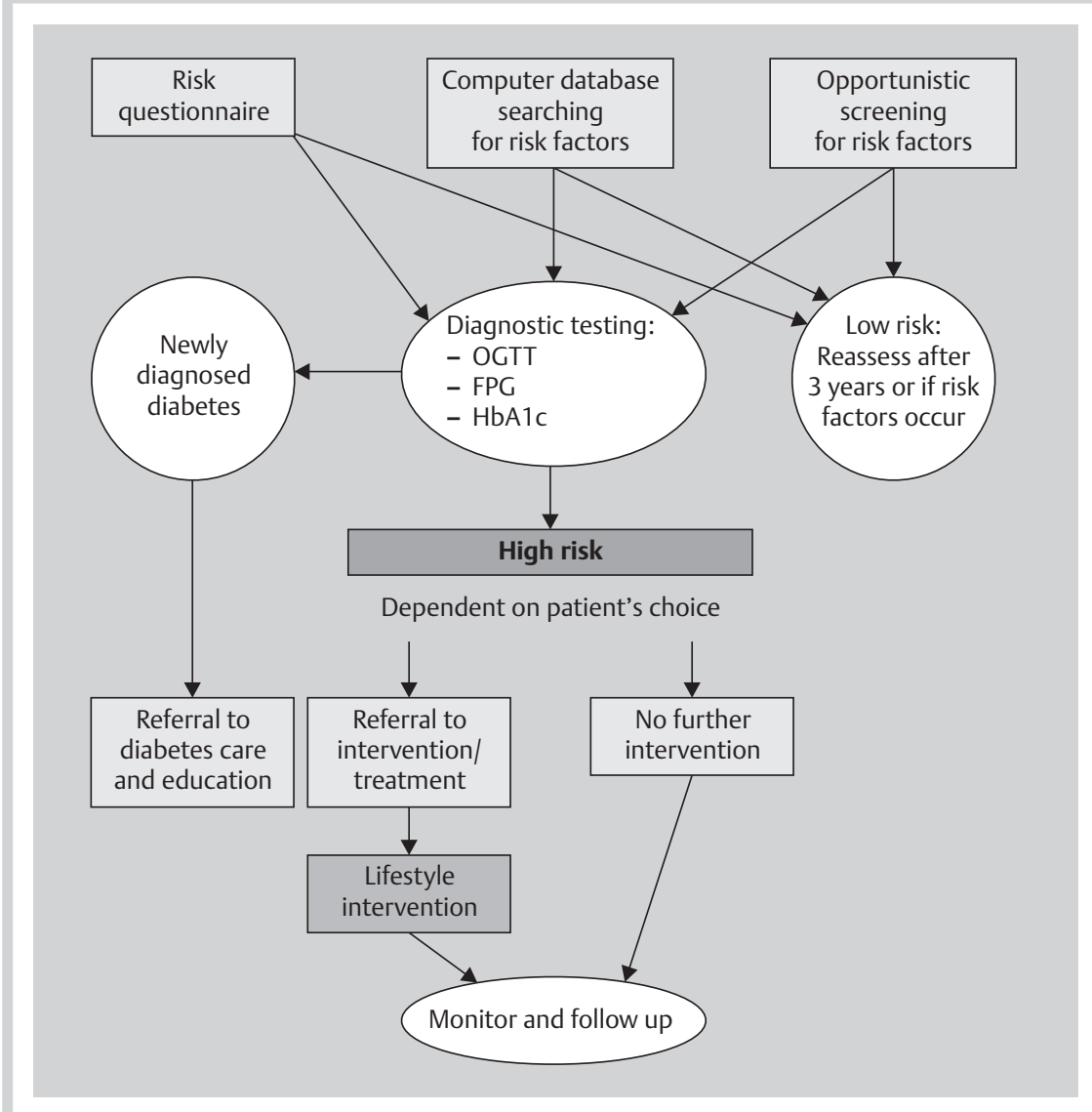

Fig. 3 Care pathway for healthcare provider. For further details, please see "IMAGE-Guideline for diabetes prevention" [15].

Strategies and practical tips for encouraging participation in intervention activities

- Personalise risks and benefits: "How would diabetes affect your life?"

- Emphasise short-term positive benefits, rather than long-term threats: "If you do this, you will lose weight and increase your energy levels/feel good about yourself (as well as reducing your risk of getting diabetes)"

- Watch your language: Don't talk about "patients" but about "clients" - the people you are working with are not ill yet! Focus on health not on illness

- Use your prevention network for communication and motivation: e.g. physicians and pharmacists have a high credibility and thus could act as "recruiters" and motivators

- Ensure that the health professionals making the referrals are aware of the benefits of the prevention programme and if appropriate, take steps to strengthen their belief that intervention programmes are valuable

- Initiate a "snow-ball system": Ask clients you treat to disseminate the FINDRISC questionnaire to their relatives and friends

- Offer incentives

- Offer choices in the mode of intervention delivery (group, individual, information for self-help)

- If the person is not willing or able to participate now, ask again later; it is never too late to get benefits from lifestyle change!

\section{How to Change Behaviour}

$\nabla$

\section{Elements of an effective lifestyle intervention programme}

Changing behaviour is a complex process. Helping a person to change an existing behaviour requires:

- Individually tailored intervention and advice

- Support for developing motivation to make changes, goal-setting \& action planning

- Ongoing support and encouragement to maintain change \& advice on how to manage setbacks

O Fig. 4 is a model which shows the processes involved in behaviour change. Examples of the possible content for three behaviour change sessions (Initiating motivation; Taking action; Maintaining motivation) can be found in the appendix.

Important considerations when supporting behaviour change:

1. Responsibility for changing behaviour: Behaviour change is the responsibility of the individual but with support from healthcare providers. Try to create a relationship of "equal expertise"; the individuals are experts on their circumstances and what works for them; the healthcare providers have expert information, which may be useful to the individual

2. Empowerment: Focus on empowering the individual. Behaviour change is not a passive process and only the individual concerned can make the necessary changes. Give encouragement and help develop the client's confidence that he/she will be able to do this

3. Choice: It should always be the individual's choice to change a behaviour. Present clients with all relevant information and support them through the decision making process. If an indi- 


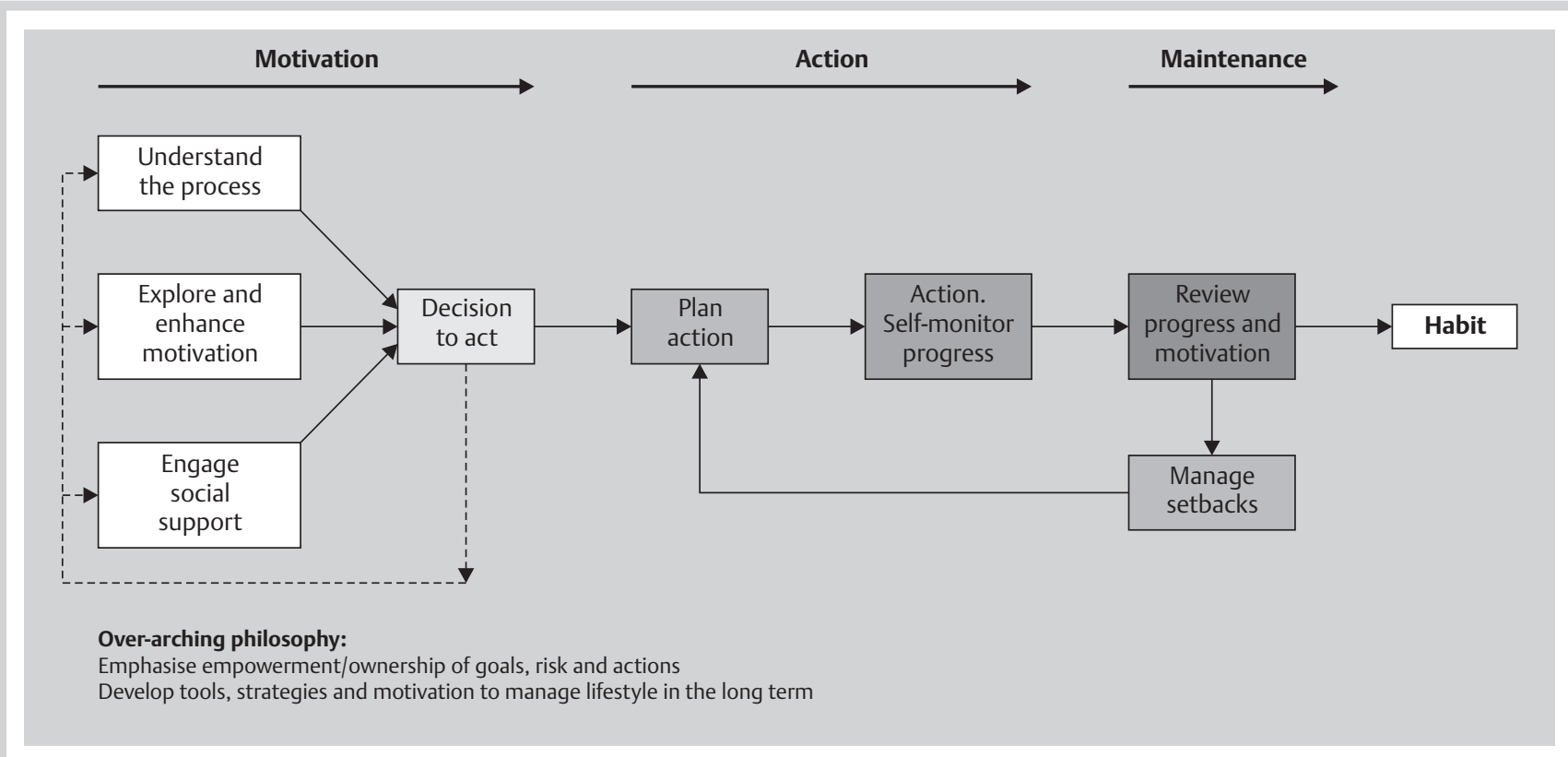

Fig. 4 A process model for supporting lifestyle behaviour change. Source: Sheppard \& Greaves, 2009.

vidual is confident, feels it is important, and is ready to change a behaviour, then an action plan can be made. If he/she does not feel ready to change this decision must be respected. Clearly state that the door is always open for future discussions and decisions.

4. Support: The amount of support individuals need will vary. Everyone is different and tailoring the intervention to suit the individual is essential

\section{An intervention programme for behaviour change}

should include: (see Appendix for more details)

- Support for changes in diet and physical activity

- Support for self-monitoring \& self-regulation - encourage individuals to monitor physical activity levels and what they eat (activity and food diaries may be helpful if the patient is willing) \& encourage personal management of their behaviour change (i.e. regular reflection on progress with a focus on identifying what works and problem solving, as below).

- Goal-setting - plan when, where, and how to perform the new behaviour. Ensure goals are SMART: specific, measurable, achievable, relevant, and time-framed. Consider setting both short-term goals and long-term goals

- Action planning - An action plan should include three sections: a) Clear goals

b)Clear information on who is providing social support, where and when the support will happen and

c) Coping strategies on how to deal with problems that may occur

- Coping strategies \& problem solving - explain how to identify and cope with barriers that stop individuals achieving their goals, and how to solve/deal with problems when they occur (i.e. how their plans can be revised to work better).

- Social support - engage others who are important such as family, friends and peers, to help support/encourage behaviour change. Support may be emotional, practical or informational (e.g. help with planning activities). Encourage clients to invite a supporter along to sessions if they wish.
- A strong focus on strategies which help maintain changes in behaviour - for example, using relapse management strategies (e.g. explaining that setbacks are normal and provide useful learning experiences, identify what has caused any setbacks and make new coping plans to deal with these barriers to change).

Supporting people to undertake behaviour change is not simple and ideally it requires appropriate training. An effective intervention can be delivered either individually (face-to-face) or in a group setting (see the Appendix for example "behaviour change session plans"). The selection of intervention mode should be based on local facilities, resources, and client preferences. Additional education content on physical activity and healthy diet should be integrated into the programme (see subsequent sections).

\section{Time frame for implementing a lifestyle intervention programme: An example}

A lifestyle intervention programme could run over a 5-week period with additional maintenance sessions in the following 6 . Core active intervention sessions are once a week for the first 3 weeks; Week 1 develop motivation, Weeks 2 \& 3 make decisions, learn coping strategies, develop an action plan. Week $\mathbf{5}$ is after a two week gap to allow individuals to go away and try out their action plan and find out what works and what does not. Week $\mathbf{5}$ is the first maintenance session, involving progress review and relapse management. Education on diet and physical activity (ideally including active learning techniques) should be interspersed with or integrated within the behaviour change sessions; although it is recommended to establish motivation prior to any detailed educational input. Further maintenance sessions can then be accessed at gradually longer periods as the need for support reduces, e.g. after one month, two months and then three months.

A suggested timeline for the intervention is in the Appendix (๑ Fig. 7). 
Table 1 The F.I.T.T. principle for combining cardiorespiratory endurance training and resistance training

\begin{tabular}{|c|c|c|c|}
\hline \multicolumn{2}{|c|}{ F.I.T.T. principle } & \multirow{2}{*}{$\begin{array}{l}\text { Aerobic endurance training } \\
3 \times / \text { week (minimum), max. } 2 \text { days gap between training sessions }\end{array}$} & \multirow{2}{*}{$\begin{array}{l}\text { Resistance training } \\
2-3 \times / \text { week }\end{array}$} \\
\hline F requency & How often & & \\
\hline I ntensity & How hard & $\begin{array}{l}\text { (a) light to moderate }\left(40-60 \% \mathrm{VO}_{2} \mathrm{max} / 50-70 \% \mathrm{HRmax} \text { ) (e.g. brisk }\right. \\
\text { walking }-5-6 \mathrm{~km} / \mathrm{h}) \text { (slightly increased breathing rate) (b) vigorous } \\
\text { (e.g. jogging }-8-10 \mathrm{~km} / \mathrm{h} \text { ) (increased breathing rate and sweating) }\end{array}$ & light to moderate (slight muscular fatigue) \\
\hline T ime & How long & $\begin{array}{l}\text { (a) light to moderate } 45-60 \mathrm{~min} \text { (in total > } 150 \mathrm{~min} / \text { week) (b) vigorous } \\
30-40 \mathrm{~min} \text { (in total > } 90 \mathrm{~min} / \text { week) }\end{array}$ & $1-3$ sets of $8-15$ repetitions for each exercise \\
\hline Type & What kind & walking, jogging, cycling, swimming, hiking, skiing & $\begin{array}{l}\text { about } 8 \text { different strength exercises (using the } \\
\text { major muscles of the body) (e.g. with fitness } \\
\text { machines, resistance-bands or just with your own } \\
\text { body weight) }\end{array}$ \\
\hline
\end{tabular}

\section{Intervention intensity}

Aim to maximise the frequency of contact or number of contacts, particularly in the active intervention phase (the stage where motivation is established, plans made and new behaviour(s) initiated and practised). Clearly the ability to do this will depend on the resources available.

\section{Effective communication}

When discussing lifestyle change with clients it is important to avoid a solely advice-giving approach. To improve on how you communicate with individuals focus on three areas:

Speaking: focus attention on speaking with clarity and purpose

- Use understandable words.

- Be non-judgemental and respectful.

- Moderate rate of speech.

Active listening: concentrate attention on the person speaking and closely follow what is being said

- Reflect on what the client says and clarify their position.

- Show interest in the patient's ideas and encourage/praise any positive "change talk".

- Summarise what has been said.

- Extend or interpret their ideas - ask if your interpretation is correct.

Non-verbal communication: A large proportion of communication is non-verbal and it may be consistent or contrasting to what is said

- Maintain good eye contact

- Use a tone of voice similar to the person seeking help

- Occasional heading nodding, smiling, hand gestures where appropriate

One approach which can be used to discuss lifestyle change is motivational interviewing (MI). MI is a directive, person-centred counselling style which aims to enhance individuals' intrinsic motivation to change behaviour by exploring and resolving ambivalence. In this counselling style the relationship between the individual and the professional is more like a partnership than an expert/recipient relationship. The professional respects the individual's autonomy and freedom of choice (and consequences) regarding her or his own behaviour.

\section{Physical Activity to Prevent Diabetes}

$\nabla$

The term physical activity includes the full range of human movement, from activities of daily living and active hobbies, to exercise and competitive sport.

\section{WHY increase physical activity?}

Physical activity is one of the main pillars in the prevention of diabetes. Being physically active leads to various health enhancing adaptations (reduced blood pressure, reduced resting heart rate, improved body composition (e.g. through reduced abdominal adiposity), improved lipid profiles and improved glucose homeostasis, improved insulin sensitivity, reduced systemic inflammation, improved psychological well-being).

\section{HOW to encourage your client to increase physical activity?}

Changing habits is difficult for everybody. Therefore, it is important to motivate your clients to start, and then to keep being physically active. The following advice/key messages will help you to give adequate support:

- Increase awareness of the need to be active

- Discuss client's history of physical activity

- Discuss pros and cons of increasing physical activity

- Help to set realistic and individual goals

- Increase daily physical activity, because every single bout of physical activity is useful (e.g. walking, gardening, etc.)

- Advise your client to be physically active for at least 30 min on a minimum of 5 days a week

Preferably a combination of cardiorespiratory endurance training and resistance training*

- Encourage the adoption of enjoyable physical activities as having fun is an important factor in keeping active

- If your client has co-morbidities recommend that they have a physician consultation before starting vigorous exercise

* To educate about how to gain training benefits from a combination of cardiorespiratory endurance training and resistance training, we can apply the F.I.T.T. principle (see $\bullet$ Table 1).

Please keep in mind that these are general guidelines for individuals of moderate fitness levels. The F.I.T.T. recommendations are based on "optimal figures" and sometimes they may not be reached by someone in the target group. Hence, it may be necessary to break down the recommendations into gradual steps in order to avoid physical and mental overload. Remember that ANY increase in physical activity from the client's baseline level is likely to be beneficial.

\section{Nutrition and Dietary Guidance to Prevent Diabetes $\nabla$}

A balanced, nutritious, enjoyable diet is essential for health. It also gives pleasure and psychological and social well-being. Sustained weight loss of $5 \%$ or more in overweight people lowers 


\section{Goals for food intake}

- Consuming fruit, vegetables, and legumes in abundance ( $\geq 500 \mathrm{~g}$ or five portions per day)

- Choosing whole grain in all cereal products

- Limit sugar to $\leq 50 \mathrm{~g} /$ day, including sugar in food and beverages

- Consuming vegetable oil and/or soft margarines and/or nuts as the primary source of fat

- Limiting butter, other saturated fat and partially hydrogenated fats

- Choosing low-fat milk and meat products

- Consuming fish regularly ( $\geq 2$ per week)

- Consuming alcoholic beverages in moderation ( $\leq 2$ drink/day for men and $\leq 1$ drink/day for women) if at all

- Other goals according to individual needs (e.g. body weight, diseases, medications, age)

\section{Goals for long-term nutrient intake}

- Energy intake balanced with physical activity levels to achieve or maintain healthy body weight

- Total fat 25-35 E\%* (60-80 g/day with 2000 kcal daily intake level), of which saturated or trans fat $\leq 10 \mathrm{E} \%$

- Dietary fibre 25-35 g/day

- Salt $(\mathrm{NaCl}) \leq 6 \mathrm{~g} /$ day

- Alcohol $\leq 5 \mathrm{E} \%$
Table 2 Dietary recommendations for diabetes prevention

* $\%$ = proportion of total energy

Table 3 The Eat Clever principle* provides brief practical advice for counsellors

\section{Eat Clever}

Estimation of the dietary pattern compared to the recommendations

Aims in the long and short term

Tools, guidance and support

Composition of the diet

Lifestyle for the whole life

Energy

Variety

Evaluation

Risks management
Use the food diary, or interview to help your client to become aware of his/her dietary pattern and food consumption. Compare dietary intake to the recommendations. Consider special needs, resources and readiness to change food habits. Discuss both short and long term goals: what is your client willing and able to do at the moment? Help to set practical, achievable targets and proceed with small steps. Make a plan with your client.

Which kind of tools, guidance, support or skills are needed and available? Involving the family and friends and group counselling are all worth considering.

A diet with high sugar and other refined carbohydrates and low fibre content, or high saturated and trans fat content may increase the risk for diabetes and other related disorders. Whole grains and moderate amounts of coffee and alcohol may decrease the risk. Encourage the use of herbs and spices to reduce salt. Refer to your national nutrition recommendations but consider the special requirements of people with high diabetes risk, such as the improvement of the components of the metabolic syndrome. Take into account any additional disease your client may have.

Diet is influenced by culture, religion, ethical, physiological, psychological, social and economical aspects, availability, and individual likes and dislikes. Help your client to find his/her own healthy way of life. Lifestyle change is a process and relapses are part of it. Help your client to learn from these experiences to develop successful strategies over time.

Excessive energy intake causes weight gain. If the client is overweight, make a plan with her/him to support gradual weight loss (step by step). Focus on substituting foods with high saturated fat and/or refined carbohydrate content with lowerenergy items. How many meals and snacks, beverages and alcohol included, does he/she have during a day and night? Some regularity in the daily meal plan helps to control over-eating.

Emphasise variety instead of restriction. A health-promoting diet provides satiety and pleasure as well as protective nutrients. Encourage clients to try new foods. Give advice on how to read food labels. This can help your client to feel more confident and expand their healthy food choices.

Evaluation and self-monitoring help in achieving and maintaining new food habits. Body weight and/or waist circumference should be measured regularly. Encourage your client to use a food diary (see Appendix) or some other methods to monitor eating habits: the number of meals and snacks, the amounts of certain food stuffs, such as vegetables, whole grains, sugar, alcoholic beverages, vegetable oil and/or fat etc.

Dietary guidance must be based on evidence from nutrition and behavioural sciences. Focus on the big picture: changing one aspect in the diet affects many others. Strict restrictions and "crash dieting" may lead to an unhealthy diet, and can cause damage in the long term as well as psychological and social harm. A multi-disciplinary team, including a registered dietician and a psychologist, can give essential support to avoid these risks.

* Please apply these principles in the framework of your national recommendations

diabetes risk substantially. Modification of the diet towards a healthier composition further reduces the risk and also improves risk factors for cardiovascular diseases ( $\odot$ Tables 2 and 3).

\section{Other Behaviours to Consider \\ $\nabla$}

\section{Smoking}

Smoking is a well-established risk factor for many chronic diseases, including diabetes and its complications. As well as other harmful effects, smoking increases visceral fat accumulation and insulin resistance. All smokers should be encouraged to quit smoking. However, weight gain is common with smoking cessation and therefore dietary advice on avoiding weight gain should be given alongside smoking cessation advice (e.g. managing cravings and withdrawal symptoms by using short bouts of physical activity as a stress-relief activity, rather than eating snacks). Referral to local smoking cessation groups and direction to information on the Internet may be advisable. Pharmacotherapy or nicotine replacement therapy may be helpful in selected cases. 


\section{Stress and depression}

There is increasing evidence of a link between depression and both diabetes and cardiovascular disease. This suggests that it may be of value to pay attention to the presentation of depressive symptoms in obese people. Should you suspect someone has symptoms of depression or stress, consider referring to a physician/counsellor/psychologist.

\section{Sleeping patterns}

Both short ( $<6 \mathrm{~h}$ ) and long $(>9 \mathrm{~h}$ ) sleep durations may have associations with increased risk of developing diabetes. Sleep deprivation may impair the balance of hormones regulating food intake and energy balance.

Discuss with your clients their sleeping habits and patterns. Long sleep durations may be a marker of sleep-disordered breathing or depression and should be treated appropriately. There is also a close association between obesity and obstructive sleep apnoea syndrome.

\section{Evaluation and Quality Assurance \\ $\nabla$}

Evaluation and continuous quality assurance are essential elements of a successful primary prevention programme. It is important to use them in a structured way to evaluate whether you are doing the right things and to allocate resources in the most effective way.

To obtain valid and reliable indicators, measurements and methods should be standardised and valid. In addition to needs of internal quality assurance, unified quality standards are necessary for systematic evaluation and reporting at the national and at the EU level. The IMAGE evaluation and quality assurance data collection template (see Appendix) suggests recommended content for evaluation data which can be further adapted to local needs and circumstances.

For further details, please see the "IMAGE quality indicator" report [14]. It provides a more comprehensive approach, detailed background information, and references for the recommended measurement protocols. It includes different types of quality assurance tools and presents quality indicators for different prevention strategies, as well as scientific evaluation indicators and measurement standards to be used if scientific analysis and reporting are planned.

\section{Risks and Adverse Effects}

Compared to drug-based therapies, side-effects of lifestyle interventions are typically mild and transient. Furthermore, the benefits of a sustained lifestyle change can be assumed to be much larger, as changing lifestyle can have a number of additional effects on the human body and mind (improved quality of life, energy, mobility and self-esteem, reduction in depression and cardiovascular risk factors), which can be seen as "positive side effects". Time-limited interventions which lead to sustained lifestyle changes can have long lasting effects. Using a drug treatment for diabetes prevention treats one targeted risk factor (i.e. lowering glucose) and the effect normally disappears after the individual stops taking the drug. For patients who do not respond to lifestyle change, pharmaceutical options may be beneficial. However, a sustained lifestyle change is the safest form of a therapy for people with increased diabetes risk.

\section{Join Forces to Make a Difference! \\ $\nabla$}

If we work together using this strong evidence base we can halt, or at the very least delay the progression of diabetes and positively impact the quality of life of the millions of people who are at high risk of diabetes.

\section{Take Action to Prevent Diabetes. You Can Make a Difference. Do it Now!}

\section{Affiliations}

${ }^{1}$ Department of Chronic Disease Prevention, Diabetes Prevention Unit, National Institute for Health and Welfare (THL), Helsinki, Finland

${ }^{2}$ Carl Gustav Carus Medical Faculty, Technical University of Dresden, Dresden, Germany

${ }^{3}$ Department of Public Health and Clinical Medicine, Umeå University, Umeå, Sweden

${ }^{4}$ Peninsula Medical School, University of Exeter, Exeter, United Kingdom

${ }^{5}$ Jagiellonian University Medical College, Department of Endocrinology, Krakow, Poland

${ }^{6}$ IMAGE Study Group Project Manager (2007-2009), Munich, Germany

${ }^{7}$ Niederrhein University of Applied Sciences, Mönchengladbach, Germany

8 Prevention Project of Diabetes and Cardiovascular Diseases, Pirkanmaa Hospital District, Tampere, Finland

9 Vice-President, European Association for the Study of Obesity (EASO) and Obesity Research Unit, Helsinki University Central Hospital, Helsinki, Finland

${ }^{10}$ Karl-Landsteiner Institute for Endocrinology and Metabolism, Vienna, Austria, and Institute for Clinical Diabetology, German Diabetes Center, and Department of Metabolic Diseases, Heinrich-Heine University Düsseldorf, Düsseldorf, Germany

${ }^{11}$ Institute of General Practice and Community Medicine, University of Oslo, Oslo, Norway

12 Hjelt Institute, Department of Public Health, University of Helsinki, Helsinki, Finland, and South Ostrobothnia Central Hospital, Seinäjoki, Finland, and Spanish Diabetes Foundation, Madrid, Spain

${ }^{13}$ Kaunas University of Medicine, Institute of Endocrinology, Kaunas, Lithuania

${ }^{14}$ Bergische Universität Wuppertal, Germany

The following references have been used in the Toolkit: [1-26]

\section{References}

1 Alberti K, Eckel RH, Grundy SM, Zimmet PZ, Cleeman JI, Donato KA, Fruchart J-C, James PT, Loria CM, Smith SC. Harmonizing the metabolic syndrome - a joint interim statement of the International Diabetes Federation Task Force on Epidemiology and Prevention; National Heart, Lung, and Blood Institute; American Heart Association; World Heart Federation; International Atherosclerosis Society; and the International Association for the Study of Obesity. Circulation 2009; 120: 1640-1645

2 British Psychological Society Health Psychology Team; Michie NRS, Fussell A, Hardeman W, Johnston M, Newman S, Yardley L. Improving health: Changing behaviour. NHS Health Trainer Handbook. London: Department of Health; 2008

3 Finnish Diabetes Association. Programme for the prevention of type 2 diabetes in Finland. Available at: 2003: http://www.diabetes.fi/english/prevention/programme/index.html

4 Gillies CL, Abrams KR, Lambert PC, Cooper NJ, Sutton AJ, Hsu RT, Khunti K. Pharmacological and lifestyle interventions to prevent or delay type 2 diabetes in people with impaired glucose tolerance: systematic review and meta-analysis. BMJ 2007; 334: 299-302

5 Hjellset $V$, Bjorge B, Eriksen $H$, Hostmark A. Risk factors for type 2 diabetes among female Pakistani immigrants: The InvaDiab-DEPLAN study on Pakistani immigrant women living in Oslo, Norway. J Immigr Minor Health 2009; Epub ahead of print Sep. 25, 2009; DOI: 10.1007/s10903009-9290-3

6 Hussain A, Bjorge B, Telle-Hjellset V, Holmboe-Ottesen G, Raberg M, Wandel M. Body size perceptions among Pakistani women in Norway participating in a controlled trial to prevention deterioration of glucose tolerance. Ethnicity and Health 2010 [in press]

7 International Association for the Study of Obesity. Adult overweight and obesity in the European Union (EU27). London; 2009. Available at: www.iaso.org

8 International Diabetes Federation. IDF Diabetes Atlas, fourth edition. Available at: IDF ed; 9 July 2009: www.eatlas.idf.org 
9 Knowler W, Barrett-Connor E, Fowler SE, Hamman RF, Lachin JM, Walker $E A$, Nathan DM. Reduction in the incidence of type 2 diabetes with lifestyle intervention or metformin. New Engl J Med 2002; 346: 393-403

10 Laatikainen T, Dunbar JA, Chapman A, Kilkkien A, Vartiainen E, Heistaro S, Philpot B, Absetz P, Bunker S, O'Neil A, Reddy P, Best JD, Janus ED. Prevention of type 2 diabetes by lifestyle intervention in an Australian primary health care setting: Greater Green Triangle (GGT) Diabetes Prevention Project. BMC Public Health 2007; 7: 249

11 Lindström J, Ilanne-Parikka P, Peltonen M, Aunola S, Eriksson JG, Hemiö $K$, Hämäläinen $H$, Härkönen P, Keinänen-Kiukaanniemi S, Laakso M, Louheranta A, Mannelin M, Paturi M, Sundvall J, Valle TT, Uusitupa M, Tuomilehto J, on behalf of the Finnish Diabetes Prevention Study Group. Sustained reduction in the incidence of type 2 diabetes by lifestyle intervention: The follow-up results of the Finnish Diabetes Prevention Study. Lancet 2006; 368: 1673-1679

12 Mann JI, De Leeuw I, Hermansen K, Karamanos B, Karlström B, Katsilambros N, Riccardi G, Rivellese AA, Rizkalla S, Slama G, Toeller M, Uusitupa $M$, Vessby B; Diabetes and Nutrition Study Group (DNSG) of the European Association. Evidence-based nutritional approaches to the treatment and prevention of diabetes mellitus. Nutr Metab Cardiovasc Dis 2004; 14: 373-394

13 Miller WR, Rollnick S. Motivational interviewing: Preparing people for change (2nd ed). New York: Guildford Press; 2002

14 Pajunen P, Landgraf R, Muylle F, Neumann A, Lindström J, Schwarz PE, Peltonen M, for the IMAGE Study Group. Quality indicators for the prevention of type 2 diabetes in Europe - IMAGE. Horm Metab Res 2010; 42 (Suppl. 1): S56-S63

15 Paulweber B, Valensi P, Lindström J, Lalic NM, Greaves CJ, McKee M, Kissimova-Skarbek K, Liatis S, Cosson E, Szendroedi J, Sheppard KE, Charlesworth K, Felton AM, Hall M, Rissanen A, Tuomilehto J, Schwarz PE, Roden $M$, for the Writing Group, on behalf of the IMAGE Study Group. A European evidence-based guideline for the prevention of type 2 diabetes. Horm Metab Res 2010; 42 (Suppl. 1): S3-S36

16 Perk J. Risk factor management: a practice guide. Eur J Cardiovasc Prev Rehabil 2009; 16 (Suppl. 2): S24-S28

17 Sigal R, Kenny G, Boule N, Wells G, Prud'home D, Fortier M, Reid R, Tulloch $H$, Coyle D, Phillips P, Jennings A, Jaffrey J. Effects of aerobic training, resistance training, or both on glycemic control in type 2 diabetes. A randomized trial. Ann Intern Med 2007; 147: 357-369

18 Steyn N, Lambert E, Tabana H. Conference on "Multidisciplinary approaches to nutritional problems". Symposium on "Diabetes and health". Nutrition interventions for the prevention of type 2 diabetes. Proc Nutr Soc 2009; 68: 55-70

19 The Diabetes Prevention Program Research Group. Reduction in the incidence of type 2 diabetes with lifestyle intervention or metformin. $\mathrm{N}$ Eng J Med 2001; 346: 393-403

20 Tuomilehto J, Lindström J, Eriksson JG, Valle TT, Hämäläinen H, IlanneParikka P, Keinänen-Kiukaanniemi S, Laakso M, Louheranta A, Rastas M, Salminen V, Uusitupa M; Finnish Diabetes Prevention Study Group. Prevention of type 2 diabetes mellitus by changes in lifestyle among subjects with impaired glucose tolerance. N Eng J Med 2001; 344: $1343-1350$

21 Warburton D, Nicol C, Bredin S. Health benefits of physical activity: the evidence. CMAJ 2006; 174: 801-809

22 Warburton DE, Nicol CW, Bredin SSD. Prescribing exercise as preventive therapy. CMAJ 2006; 174: 961-974

23 World Health Organization. Diet, nutrition and the prevention of chronic diseases. Report of a joint FAO/WHO consultation. WHO Technical Report Series No. 916. Geneva: World Health Organization; 2003

24 World Health Organization. Intervention on diet and physical activity: What works: summary report 2009. Available at: www.who.int/dietphysicalactivity/summary-report-09.pdf

25 World Health Organization, IDF. Definition and diagnosis of diabetes mellitus and intermediate hyperglycemia. Report of WHO/IDF consultation. Geneva, Switzerland: WHO Document Production Services; 2006

26 Yamaoka K, Tango T. Efficacy of lifestyle education to prevent type 2 diabetes: a meta-analysis of randomized controlled trials. Diabetes Care 2005; $28: 2780-2786$

\section{Appendix}

\section{List of Appendices}

$\nabla$

- Checklist "How to start"

- Spreadsheet/budget calculation for program costs

- Risk screening tools

- Finnish diabetes risk score FINDRISC

- Challenges of working with special consideration groups

- Example behaviour change session plans

- Physical activity diary

- Food diary

- IMAGE evaluation and quality assurance data collection

- The development of the IMAGE toolkit for diabetes prevention

\section{Checklist "How to start"}

\section{Preparatory phase}

1. When you plan a diabetes prevention programme, think big and holistically, beyond your initial target group, think about ages, ethnic groups, and family groups. Which members of your community have the highest risk and/or are most in need of preventive activities?

2. Find out about the target groups in advance

Their network and relations

Where they live/work etc

- What do you know about the group

- What has been done in this group before

- What worked and what did not, what were the successful factors?

3. Agree on strategic alliances. This is an aspect of great significance if you plan to carry out a prevention project.

4. The director/top management must approve the project and future involvement. Create a positive cooperative atmosphere with all employees, show respect, listen, include and involve.

5. Select suitable premises for the intervention programme, near to where participants live or work. Cooperate with local organisations, insurance companies, healthcare centres, hospitals, sports teams, schools and other.

- The premises must have rooms both for big gatherings/ meetings/lectures and rooms for individual consultations and testing.

Sufficient rooms/space for taking care of children, with activities that can keep them occupied if necessary.

- What is your main objective - what do you plan to achieve? The overall objective must be clear and concrete, and the results should be checked against the programme aims.

- Finances: Consider your funding needs and your funding sources. Create a funding plan.

- Ethics: Apply for necessary permissions and approvals for data collection (local ethics committee, data protection authorities). Be sure that you have the necessary insurances.

\section{Project description and planning}

1. Make a detailed plan including;

Timeframe - realistic estimates regarding the time schedule of different phases ( Fig. 5)

- Who - who is the target population? What is the target group familiar with, what are they lacking?

Estimated number of participants to include 


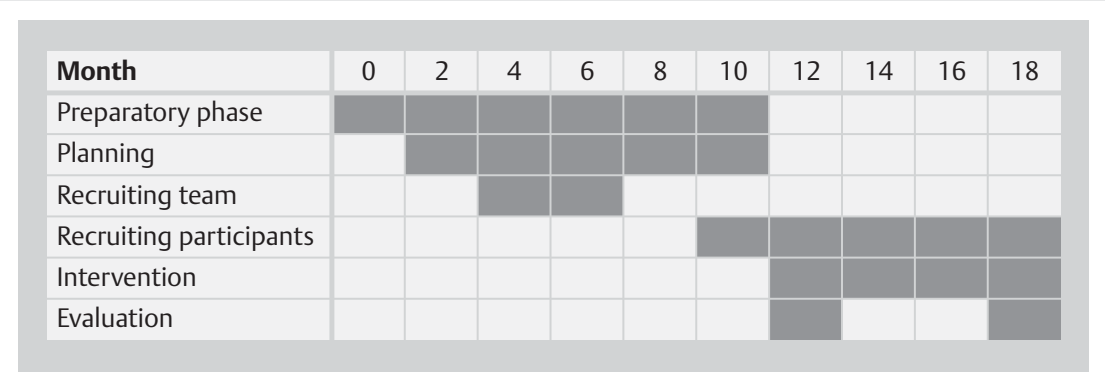

Fig. 5 Example timeframe.

How - where will the participants be recruited from, and how?

Intervention structure - group/individual sessions, content, and frequency of sessions

- Intervention content - Practical activities such as; physical activities, exercises indoor or outdoor, cooking sessions, cognitive therapy, phone interviews, Internet platforms, use of mass media etc.

Special needs - e.g. translation, limited mobility/access issues

Follow-up

\section{Recruiting project team members}

1. Selecting the optimal multi-disciplinary team is essential. It is absolutely crucial to pick team members that make the project an optimal experience for participants; this will help you with attendance rates and reduce the chance of drop-outs.

2. Decide the target group (gender, age, ethnicity - or families) before you invite collaborators.

3. Assess your capabilities and ensure that the skills of your team members are complementary and cover the wide range of skills and knowledge required (including expertise in dietary and physical activity advice and behaviour change). Team members need the following qualities:

Talent for team work

Fighting spirit

Enjoy challenges

- Respect for the participants independent of ethnicity, sex, religion, occupation, socio-economic status and attitude

4. When involving cooperating partners make sure everybody is aware of time constraints and that they understand and accept what it means to be involved in the programme.

5. The team must have and the experience and ability to work within an interdisciplinary team.

6. Everyone must talk to participants as an equal, and ensure that all participants are acknowledged, even if they are in a group.

\section{Recruiting participants}

Recruitment is a crucial part of a project.

1. Make a realistic time schedule

2. Use various identification and recruitment strategies, sources may include:

Physicians

The local health centre/occupational health services/pharmacists

Schools, workplaces

- The participants' own contacts/network
Internet

Mass media

Mailing

\section{Practical project work}

A well prepared and planned project will help to simplify the running of an intervention programme, including handling unforeseen events. Include in the project budget items that need to be ordered in advance.

1. Recruitment

Inclusion criteria, how and where to meet the participants

- Weight scale and height measurements - where is the equipment placed?

- Plastic measuring tape band for waist circumference - follow international guidelines

Questionnaires as necessary/desired

Structured documentation sheet

\section{Testing}

Blood sample supplies and equipment, blood testing, processing, storing and analyses.

Treadmill for testing of physical fitness, pedometer, activity measurements

Nutrition and physical activity diaries

Glucometers

3. Group sessions/teaching

- Computer and LCD projector

Board/clip board

Audiovisual equipment

Whiteboard

Clear and descriptive illustrations

4. Diaries for participants to make a note of physical activity and dietary behaviours

5. Physical and practical activities

Group/individuals

Indoor/outdoor

-Weather conditions, vacations, religious feasts etc.

New activities

Cooking courses

Time of day, and the time of year

6. Support materials

Toys \& drawing equipment for children

CD-player if music is wanted

Up-to-date information on teams/organisations in the area that the participants can join 


\section{Spreadsheet/Budget Calculation for Programme Costs} $\nabla$

\section{Administrative costs}

- Rental fee for use of office, meeting rooms etc.

- Project management (clerical, accountant)

- Recruitment of participants

- Information, advertising, written presentations and Internet access

- Overhead costs

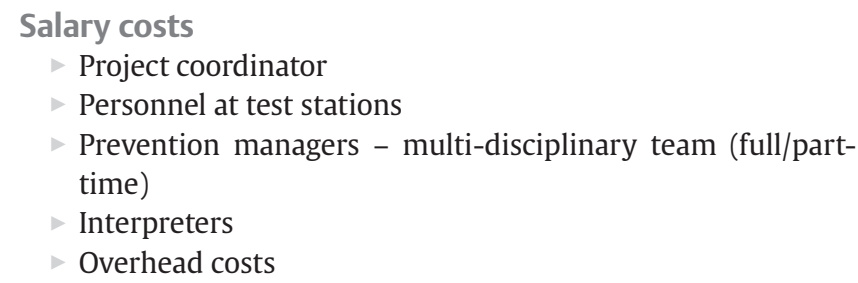

Travel and subsistence

- Meetings (programme management, networking, education)

- Travel and transport for project workers

\section{Costs for risk assessment}

- Premises and equipment for testing (i.e. blood test, analyses, questionnaires)

\section{Costs for the intervention programme}

- Premises and equipment for testing (i.e. blood tests, analyses)

- Premises and equipment for the different interventions

- Office equipment (from computers to pencils)

- Telephones and communication

- Quality management

Possible sources of incomes

- Alternative public funding

- Health insurances

- Contributions from collaborating partners

- Private funding, legacies

- Contributions from participants in seminars

- Other incomes

\section{Risk Screening Tools}

See $\bigcirc$ Tables 4 and 5.

Table 4 Risk screening tools for prevalent and incident diabetes

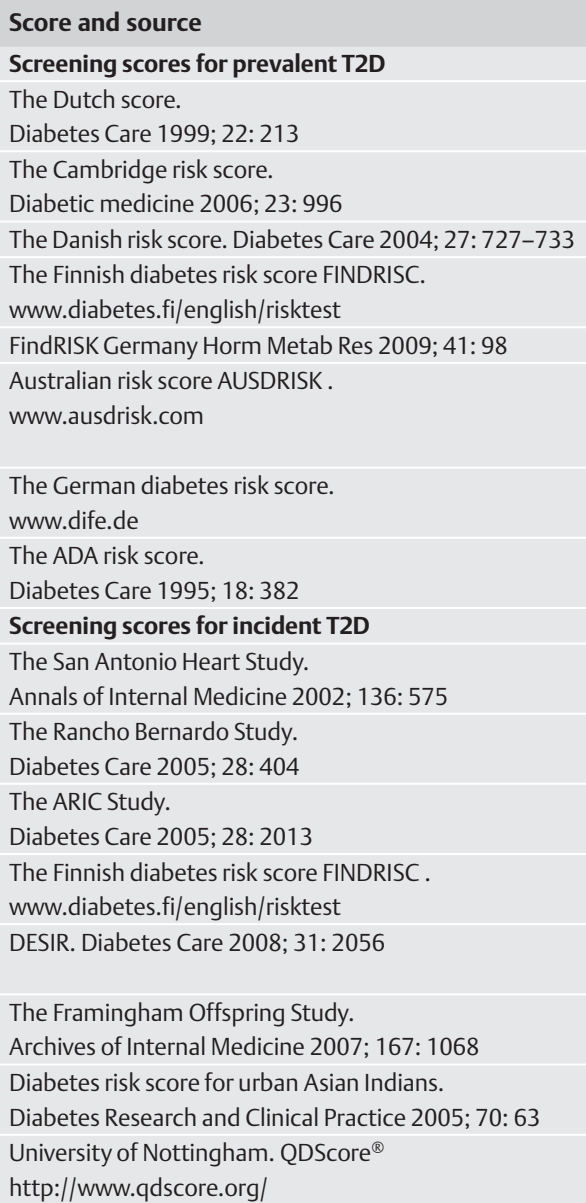

\section{Predictive variables}

Age, sex, BMI, presence of obesity, use of antihypertensive medication + family history of diabetes, physical activity Age, sex, BMI, family history of diabetes, use of antihypertensive or steroid medication, smoking

Age, sex, BMI, family history of diabetes, known hypertension, physical activity Age, BMI, waist circumference, use of antihypertensive therapy, history of high blood glucose, physica activity, consumption of fruit, vegetables and berries, family history of diabetes Age, BMI, waist circumference, use of blood pressure medication, history of high blood glucose Age, sex, ethnicity, family history of diabetes, history of high blood glucose, use of anti-hypertensive medication, current smoking status, consumption of vegetables or fruit, physical activity and waist circumference

Age, waist circumference, height, history of hypertension, physical activity, smoking, consumption of red meat, whole-grain bread, coffee, and alcohol

Age, sex, delivery of macrosomic infant, race, education, obesity, sedentary lifestyle, family history of diabetes

Age, sex, BMI, ethnicity, fasting glucose, systolic blood pressure, HDL cholesterol, family history of diabetes + 2-hour glucose, diastolic blood pressure, total and LDL cholesterol, triglyceride Age, sex, triglyceride, fasting glucose

Age, ethnicity, waist circumference, height, fasting glucose, systolic blood pressure, family history of diabetes + HDL cholesterol and triglyceride

Age, BMI, waist circumference, use of antihypertensive therapy, history of high blood glucose, physical activity, consumption of fruit, vegetables and berries, family history of diabetes Waist circumference, hypertension and smoking (M) or familial history of diabetes $(\mathrm{W})+$ fasting blood glucose

Fasting glucose, body mass index, HDL-cholesterol, triglyceride level, blood pressure, parental history of $\mathrm{T} 2 \mathrm{D}$

Age, BMI, waist circumference, family history of diabetes, physical activity

Age, sex, ethnicity, body mass index, smoking status, family history of diabetes, social deprivation, treated high blood pressure, heart disease and use of corticosteroids. 
Table 5 Finnish diabetes risk score FINDRISC

\begin{tabular}{|c|c|}
\hline & Score \\
\hline \multicolumn{2}{|l|}{ Age (years) } \\
\hline D $<45$ & 0 \\
\hline$>45-54$ & 2 \\
\hline$>55-64$ & 3 \\
\hline$\Rightarrow>64$ & 4 \\
\hline \multicolumn{2}{|l|}{ Body mass index } \\
\hline D $\leq 25$ & 0 \\
\hline$>>25-30$ & 1 \\
\hline$>>30$ & 3 \\
\hline \multicolumn{2}{|l|}{ Waist circumference $(\mathrm{cm})$} \\
\hline - men $<94$, women $<80$ & 0 \\
\hline - men $94-<102$, women $80-<88$ & 3 \\
\hline - men $\geq 102$, women $\geq 88$ & 4 \\
\hline \multicolumn{2}{|c|}{$\begin{array}{l}\text { Do you usually have at least } 30 \text { minutes of physical activity at work and/or } \\
\text { during leisure time (including normal daily activity)? }\end{array}$} \\
\hline$\rightarrow$ yes & 0 \\
\hline r no & 2 \\
\hline \multicolumn{2}{|l|}{ How often do you eat vegetables, fruit or berries? } \\
\hline - every day & 0 \\
\hline not every day & 1 \\
\hline \multicolumn{2}{|c|}{ Have you ever taken medication for high blood pressure on regular basis? } \\
\hline$>$ no & 0 \\
\hline$\checkmark$ yes & 2 \\
\hline \multicolumn{2}{|c|}{$\begin{array}{l}\text { Have you ever been found to have high blood glucose (e.g. in a health } \\
\text { examination, during an illness, during pregnancy) }\end{array}$} \\
\hline$>$ no & 0 \\
\hline$\rightarrow$ yes & 5 \\
\hline \multicolumn{2}{|c|}{$\begin{array}{l}\text { Have any of the members of your immediate family or other relatives been } \\
\text { diagnosed with diabetes (type } 1 \text { or type 2)? }\end{array}$} \\
\hline D no & 0 \\
\hline yes: grandparent, aunt, uncle or first cousin & 3 \\
\hline - yes: parent, brother, sister, or own child & 5 \\
\hline Total & \\
\hline
\end{tabular}

\section{Challenges of Working with Special Consideration Groups \\ $\nabla$}

\section{Ethnic minorities/immigrants}

- Avoid stigmatisation of any kind. Consider and talk to all individuals as equals.

- The challenges will be different for 1 st, 2 nd and 3rd generation because of language, education level, and the problems related to living in two different cultures.

- Non-western immigrants are often classified as a "low socioeconomic status group", due to low income and education. Some may have no formal education. However, this is often because they never had the opportunity to go to school, so it does not necessarily mean that they are socially deprived.

- Experiences from immigration projects indicate that the use of interpreters is essential, especially in the introduction phase. Experience from the project InnvaDiab in Norway further indicates that using local lay people as interpreters works better than using professional interpreters. In Germany the initiative MiMi (migrants for migrants) is a successful prevention initiative. The local interpreters aim to talk to the immigrants in a way that gives comfort, "especially at their own religious and cultural level". Be aware that even if immigrant participants can cope with everyday language, they may not understand medical questions or abstract questions, and it is usually not sufficient to take the right medical actions and only briefly discuss lifestyle changes.

- As healthcare workers we must be open to and able to accept the various differences between cultures. It is also important to be willing to learn about the client's culture, values and daily life. We must convey this to immigrants so that they feel that we understand and accept their distinctive characteristics. This means that we must have a clear understanding of their situation and their cultural background, both from their native country and in their new country. The need for mutual respect cannot be emphasised enough. Avoidance of misunderstandings is essential for mutual respect.

- Create a climate that allows for the clients' culture.

- Consultation at the planning stages with representatives of specific ethnic groups who are to be offered diabetes prevention programmes is essential to inform appropriate planning and adaptation.

\section{People on low incomes}

- Avoid stigmatisation of any kind. Consider and talk to all individuals as equals.

- It is vital to talk with them - not to them!

- This group is often difficult to reach, even though they have a high need to undertake lifestyle intervention programmes. They often avoid health information if, for example, they have experienced behaviour changes as overwhelming and restrictive before. The experience with those of low social status is very similar to immigrants, and we can use the same advice and follow similar procedures.

\section{Example Behaviour Change Session Plans \\ $\nabla$}

Please find below 3 example session plans, which contain ideas on how to implement a behaviour change session. The session content specified below should be integrated with education on physical activity and healthy diet. It is strongly recommended that specialised training is undertaken to gain the necessary skills and knowledge to undertake such complex work ( $\bullet$ Fig. 6 ).

\section{Structure of initiating motivation session (approx. $90 \mathrm{~min}$ ) \\ Introduction to behaviour change programme session (15 min)}

Welcome everyone \& introduce yourself. Explain overall aim of the intervention sessions, format of this session, lead an "ice breaker" activity \& agree rules for working in a group. Highlight the client-centred approach of the work: Remind participants that they are the experts in their own behaviour change; the trainer's role is to support change, not to prescribe it.

\section{Knowledge \& understanding the process of change \\ (15 min)}

1. Introduce individuals to the process of behaviour change (use diagrams \& models). Explain the importance of understanding that behaviour change is a process to work through and explain the rationale for the session.

2. Explore with the clients their prior knowledge/past experiences of behaviour change. "Has anyone tried to change a behaviour before?" "What happened?" "What helped/hindered your efforts? 


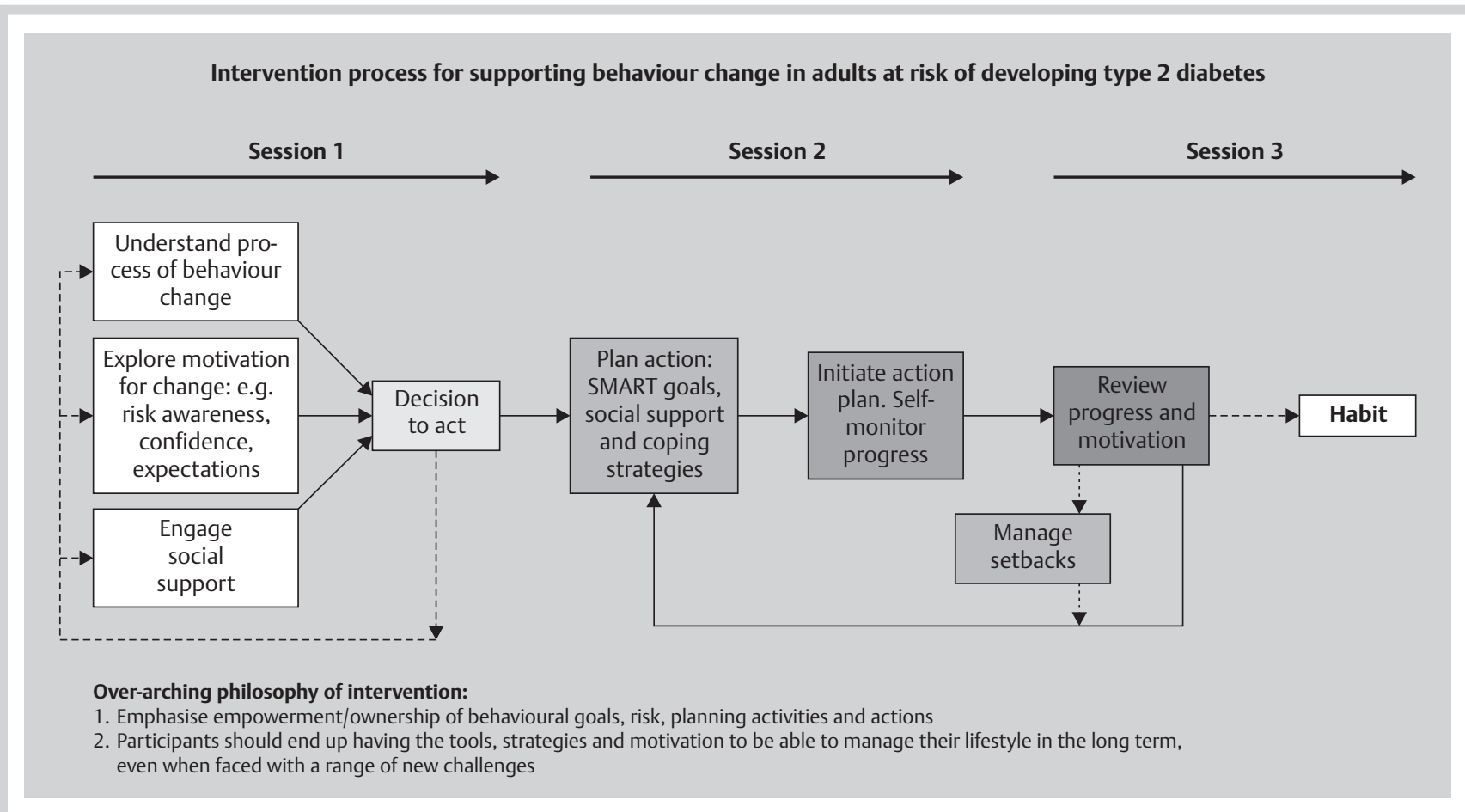

Fig. 6 Intervention process for supporting behaviour change in adults at risk of developing type 2 diabetes. Session plan.

\section{Establish motivation for behaviour change (45 min)}

1. Explore clients' perceptions of risk for developing type 2 diabetes. Ask people to suggest what the consequences of having type 2 diabetes would be. Provide information sheet on consequences and complications of type 2 diabetes. Ask clients to work out their risk scores using the risk charts/tools. Ask clients to discuss in groups what might be some of their unhealthy behaviours.

2. Explore expectations of behaviour change - what do the clients think that making changes in behaviour will lead to? Ask clients to work in groups and identify the benefits of physical activity and a healthy diet and how they prevent the development of type 2 diabetes. Emphasise strongly that it is possible to prevent the development of diabetes by changing unhealthy behaviours - so it is worth them making the effort!

3. Discuss perceived importance for change. Ask clients to think about the reasons why they are involved in the programme and why they might want to make the effort to change behaviours. Ask clients to assess how important they think it is to change their diet and getting more physically active (importance review). Ask clients to identify expected benefits and costs of changing a behaviour, write it down on a decisional balance sheet.

4. Explore confidence for change - assess clients' perceived confidence about changing their diet and/or physical activity (confidence review). How do clients feel about their ability to successfully make a change? Explore issues of confidence for physical activity/dietary change - discuss what people perceive to be barriers to change. Ask the group to think of ways round them. Ask the group to make a list of positive attributes that can help people make changes (e.g. organised, committed) and get participants to identify for themselves some that relate to them.
Social support (12 min)

Small group/pair work. Ask participants to identify positive and negative sources of social support. Ask groups/pairs to come up with ideas of how to seek more positive support and avoid negative support. Ask clients to identify their own need to develop social skills. Ask clients to identify social barriers to change. Feedback ideas to the main group (write up on flip chart). Provide information on "the best ways to provide social support" and the important role of good social support in behaviour change. Encourage participants to invite someone to the sessions who will support their attempts to change.

\section{Homework (3 min)}

Explain homework: Ask participants to use their decisional balance sheet and think about their review of their confidence and importance. Are they ready to make a change (even a small one)? Ask them to try as an experiment to change (at least for the next week) one simple habit (e.g. eating a piece of fruit once a day; going for a 10-minute walk once in the week etc.

\section{Structure of action planning session (approx. 90 min) Introduction to action planning session \\ Welcome everyone. Explain format of the session (2 min)}

\section{Review homework set in the previous session (5 min)}

Discuss with participants how easy/hard it was to complete the goal they had set themselves. What difficulties (if any) did they face? Did anything/anyone facilitate/prevent them achieving the goal? Praise all successes 


\section{Make decisions (10 min)}

Revisit perceived importance to change and confidence to change (use decisional balance sheets). Emphasise that it is very important for participants to clarify their motivations for change. Ask participants to make decisions about if they are ready to make changes and if so, what changes they want to make. Remember: it must be their decision.

Key messages on physical activity and healthy diets (20 min)

Discuss basic information on physical activity: What types? Where do you fit it in with your day-to-day life? How much to do?

Discuss basic information on healthy diets: What to eat? When to eat? How much to eat?

\section{Self-monitoring behaviour (5 min)}

Explain the importance of self-monitoring as key motivation strategy. Discuss different types of self-monitoring (diaries, pedometers etc).

\section{Create an action plan (20 min)}

1. Introduce the principles of SMART goals and practice setting SMART short- and long-term goals.

2. Action plan - Ask clients to write out as clearly as possible their action plan for behaviour change. Focus on setting SMART goals and creating a goal ladder to focus on developing a progressive series of goals that will lead to the final outcome goal. Make sure that in addition to SMART goals the action plan contains details on 1 ) what kind of social support they will need \& who will provide it and 2) what coping strategies (see below) they will use if needed ( $\bullet$ Table 6 ).

\section{Relapse prevention (25 min)}

1. Knowledge of behaviour change: Refresh clients on the process of behaviour change and emphasise the normality of setbacks. Explain that setbacks should be seen as an opportunity for learning.

2. Problem solving: Give clients tools to deal with setbacks. Explain about "high-risk" situations and "if-then" plans. Work through examples

3. Problem solving (mood/emotion): how to identify and deal with negative thoughts, moods, and stress.

4. Identify barriers to change: Address barriers and facilitators to becoming more physically active and improving diet. Look at cost, environment, emotional/cognitive and social support. Identify places \& things, people, thoughts and feelings that are or are not helpful.

\section{Homework (3 min)}

Put action plan into practice and self-monitor progress. Practice identifying negative thoughts, writing them down and countering then with positive thoughts.

\section{Structure of maintenance session (approx. 90 min) Introduction to maintenance session (5 min)}

Welcome everyone. Explain format of the session Refresh individuals on the process of behaviour change. Place emphasise on the importance of sustainable/lifelong of behaviour change and explain the rationale for, and format of, the session.

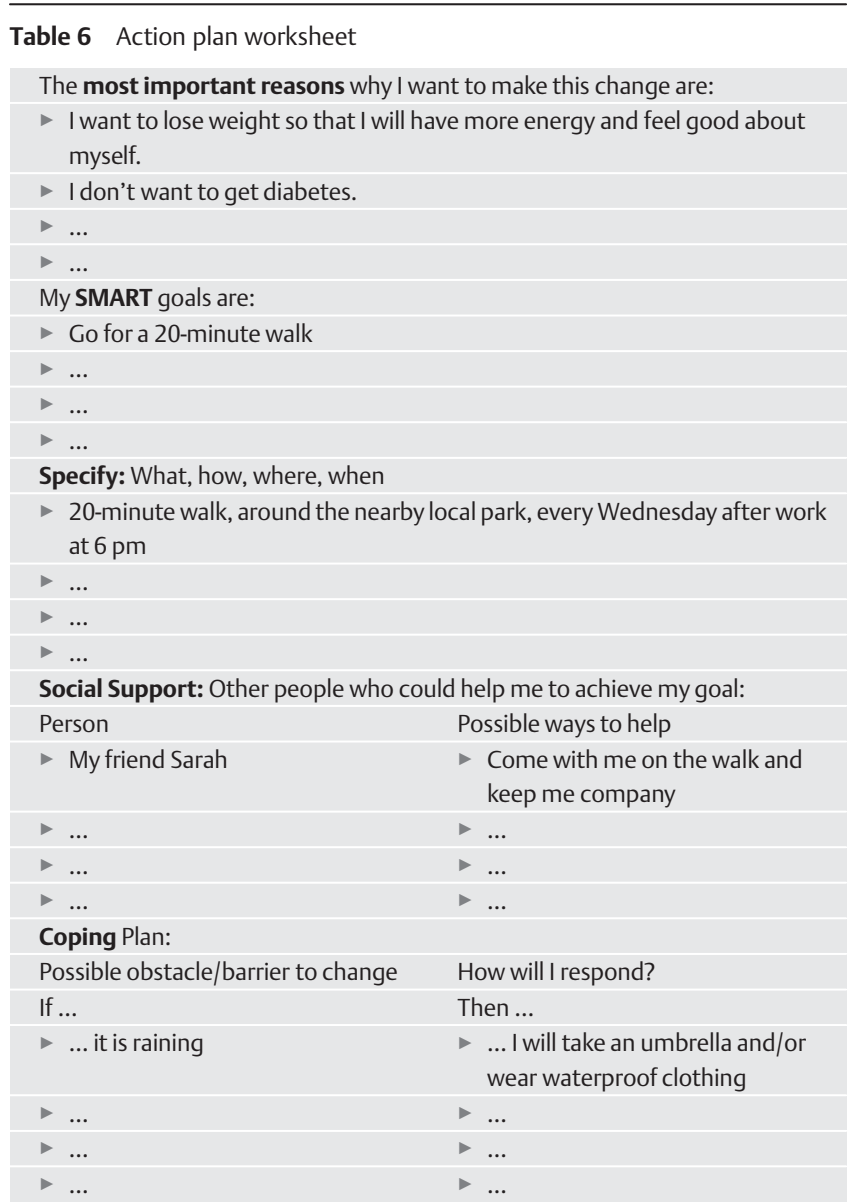

Review last session \& homework (10 min)

Ask the group to reflect on how easy/hard it has been to achieve their action plans. Did they successfully use their coping strategies? Did participants notice any negative thoughts? Were they able to stop these thoughts and reframe with positive thoughts?

\section{Discuss motivation for behaviour change ( 5 min)}

Discuss motivation for change; ask the clients "why are you making the effort to make changes?"

\section{Review progress: (20 min)}

Ask group to reflect on how easy/hard it has been to achieve their action plans. Review achievements in behaviour change in relation to 1) risk outcomes (e.g. weight, pedometer counts) 2) behavioural goals. Review goals sheet and action plan and identify achievements, surpassed goals, or goals not yet achieved. Focus on achievements. Highlight the importance of self-monitoring ask clients to evaluate their progress using their diaries, goals sheets, action plans. Review successes and setbacks. Do goals need to be re-set?

\section{Relapse management (25 min)}

Celebrate success and "re-frame" failure or setbacks as learning opportunities. Reflect on the use of coping strategies - have any been used? If so, what has worked and what has not? Identify barriers which participants have experienced. Separate into groups to discuss the barrier most relevant to them: cost, environmental, emotional, knowledge. In the group, discuss strategies to overcome the barrier and solve the problem. Feedback 


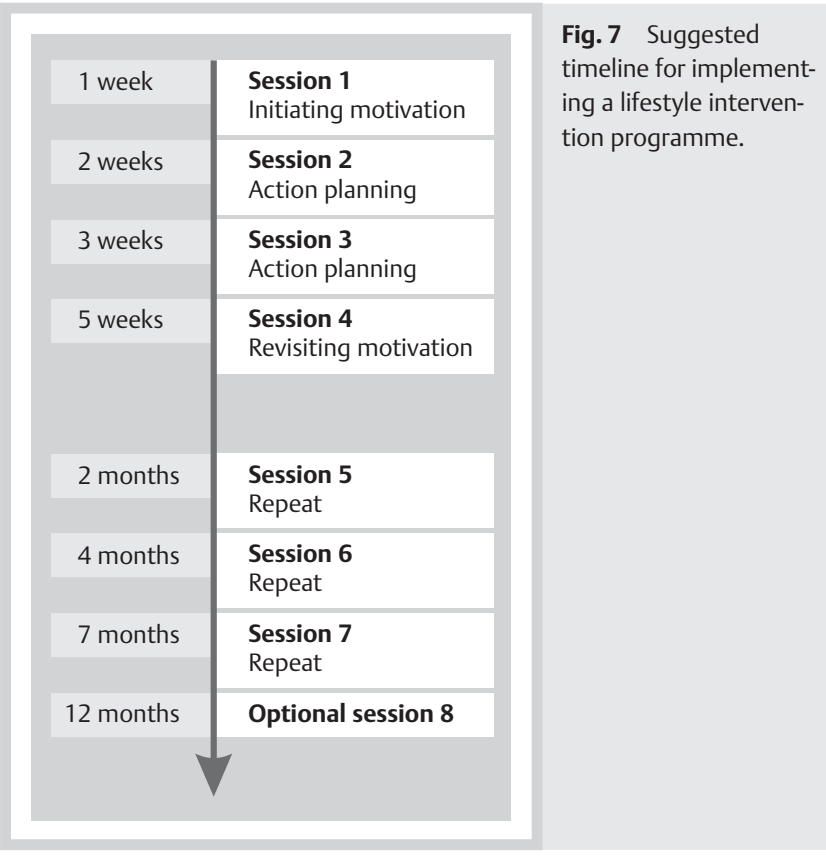

problem-solving ideas to the main group. Reinforce need for selfmonitoring of behaviour change (using pedometers, diaries etc). Explore satisfaction/dissatisfaction with behaviour change. Ask clients to talk reflect on what has worked well \& reinforce areas of satisfaction. Reframe dissatisfaction where possible or encourage goals to be re-set where unattainable. Ensure focus is on graded levels of goals so as to build success and confidence. Ask clients to think about their levels of expectation for behaviour change - are they realistic?

\section{Role of rewards (5 min)}

Highlight the importance of regularly reviewing goals and progress and rewarding achievements. What achievements are clients most proud of? Have there been any unexpected benefits to change? Ask clients to identify ways in which they can reward themselves for successes.

\section{Social support (10 min)}

Ask clients to identify positive \& negative sources of social support that they have experienced. Did the social support they put in their action plan work? If not, why not? Ask group to come up with ideas of how to seek more positive support and avoid negative support (e.g. peer pressure at mealtimes).

\section{Rewrite action plans (10 min)}

Re-write action plans (where necessary). Focus on adjusting/resetting goals (consider extending goals if desired), identifying relevant sources of social support, identifying rewards and adapting coping strategies. Conclude with a re-cap of the process of behaviour change, the normality of relapses and encourage clients to self-manage new challenges and ongoing diet and PA changes.

\section{Suggested programme timeline}

The group-based intervention programme consists of 7 sessions (with an optional 8th) for 8 to 15 people. The first 3 sessions can be completed weekly, with a 2 week break before the 4 th session to allow individuals to go away and attempt their behaviour change. The repeated maintenance sessions are completed at 2 (+1 week), 4, 7 and (optional) 12 months. NB: Education on the specifics of diet/cooking/shopping for health and physical activity should be interspersed with or integrated with the content on behaviour change ( $\bullet$ Fig. 7).

\section{SMART goals (Source: NHS health trainer handbook)}

Once the participant has decided upon a health behaviour they want to change, they need to set a goal to change their behaviour. Your role is to help the participant to set a goal that is detailed and likely to be achieved. Goals should be SMART, that is:

Specific - Measurable - Achievable - Relevant - Timely

Specific - some goals can be vague and difficult to measure. It is important to set goals that are clear and precise. For example, a vague goal would be 'being fit and healthy' whereas a clear, specific goal would be "I will work out at the local gym for at least 30 minutes three times a week at $7 \mathrm{pm}$ on Monday and Thursday and 10 am on Saturday." To help the participant make their goal more specific, ask them questions such as:

- What are you going to do?

- How are you going to do it?

- Where are you going to do it?

- When are you going to do it?

- With whom are you going to do it?

Measurable - making the goal specific means that it should be easy to measure whether or not the participant has achieved their goal. The example above, "I will work out at the local gym for at least 30 minutes three times a week at $7 \mathrm{pm}$ on Monday and Thursday and 10am on Saturday," is measurable. The participant can record the number of times they went to the gym in one week, and also how long they worked out for each time. It would be hard to measure a vague goal like "being fit and healthy".

Achievable - set goals that are within the participant's reach. Failing to achieve a goal can have a negative effect on their motivation to work towards their goal. For example, an unrealistic goal could be 'eat no chocolate or sweets for the next seven days'. A more realistic goal could be "eat no more than three portions of chocolate or sweets in the next seven days". It is important to make the first goal quite easy to achieve to boost the participant's self-confidence and encourage them to carry on. Participants should remember that the best way of changing behaviour and maintaining change is to build on small successes.

Relevant - does the participant think that the goal is relevant to them? You need to check with the participant that they see a clear link between their goal and their health or how they feel, and that it is a behaviour that they want to change.

Timely - is this goal the right thing for them to try to achieve right now? If so, set a time frame in which the goal can be achieved. If you don't set a target date for the completion of the goal, it could go on and on without the participant ever achieving it. For example, if your next session with the participant is a week away, aim for the goal to have been completed by that time. If the goal requires a longer time frame, decide together whether there are any mini-goals that the participant could achieve in time for the next session ( $\bullet$ Table 6 ). 


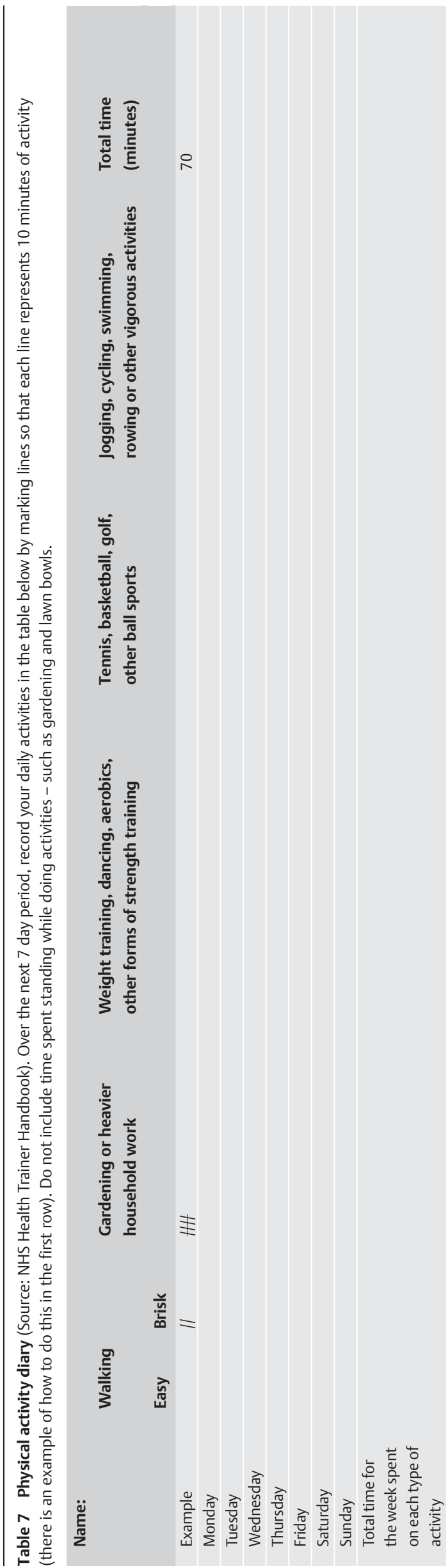

\section{Physical Activity Diary \\ $\nabla$}

See $\odot$ Table 7.

\section{Food Diary}

$\nabla$

See $\odot$ Table 8.

\begin{tabular}{|c|c|c|}
\hline \multirow[t]{2}{*}{ Name: } & \multicolumn{2}{|l|}{ Date: } \\
\hline & What you ate and drank & Notes \\
\hline$\rightarrow 9$ am & $\begin{array}{l}\text { mug of coffee with cream \& sugar, } \\
\text { croissant, glass of orange juice }\end{array}$ & ate in a hurry \\
\hline $9 a m-12$ & - & - \\
\hline $12-3 p m$ & $\begin{array}{l}\text { large pepperoni pizza, } \\
\text { can of soft drink }\end{array}$ & $\begin{array}{l}\text { busy at work, } \\
\text { so ate at my desk, } \\
\text { was really hungry! }\end{array}$ \\
\hline $3 p m-6 p m$ & $\begin{array}{l}2 \text { mugs of coffee with milk and } \\
\text { sugar }\end{array}$ & felt full \& tired \\
\hline $6 p m-9 p m$ & $\begin{array}{l}\text { steak with french fries, small salad } \\
\text { (lettuce \& tomato, no dressing), } \\
\text { pint of beer }\end{array}$ & $\begin{array}{l}\text { in a restaurant } \\
\text { with friends }\end{array}$ \\
\hline $9 \mathrm{pm} \rightarrow$ & a bag of sweets $(100 \mathrm{~g})$ & at home by TV \\
\hline
\end{tabular}

\section{Why use a food diary?}

Keeping a food diary can help your client to become more aware of his/her eating pattern: the health promoting habits and the possible problem areas. It can be an excellent tool for facilitating discussions.

Use the food diary as a basis for goal setting and planning. Later on, repeating the food diary shows what has changed over time and helps to maintain the new habits. Making a note of social surroundings and feelings during meals can also be helpful, especially if your client has particular problems, such as excessive or uncontrolled eating.

A simple template food diary is printed above, but a small notebook can be used as well. Keeping a food diary for a week would be optimal, but even a couple of days can give useful information. Explain to your client that the purpose of the food diary is to help him/her in his/her journey to better diet and well being. Ask him/ her to write down everything he/she eats and drinks, and to maintain their usual eating and drinking habits. Short notes are enough, such as "a cup of coffee with sugar and a doughnut" or "a large bowl of vegetable salad with olive oil vinaigrette and two slices of whole grain wheat bread with butter". Only if you are using the food diary to collect detailed data on nutrient intakes (e.g. for research purposes), would you need to use a more detailed and structured format.

Compare the food diary with your client's personal goals. This can be done either individually or in a small-group session. Pay attention to the number of meals and snacks during a typical day, the amount of certain types of food, such as vegetables, whole grains, deserts, alcoholic beverages, and sources of soft and hard fat. Let the client express his/her own opinions, experiences and ideas; use open-ended questions. Encourage the client to make his/her own suggestions for new solutions and further progression. Remember to give positive feedback! 
Table 9 Image evaluation and quality assurance data collection

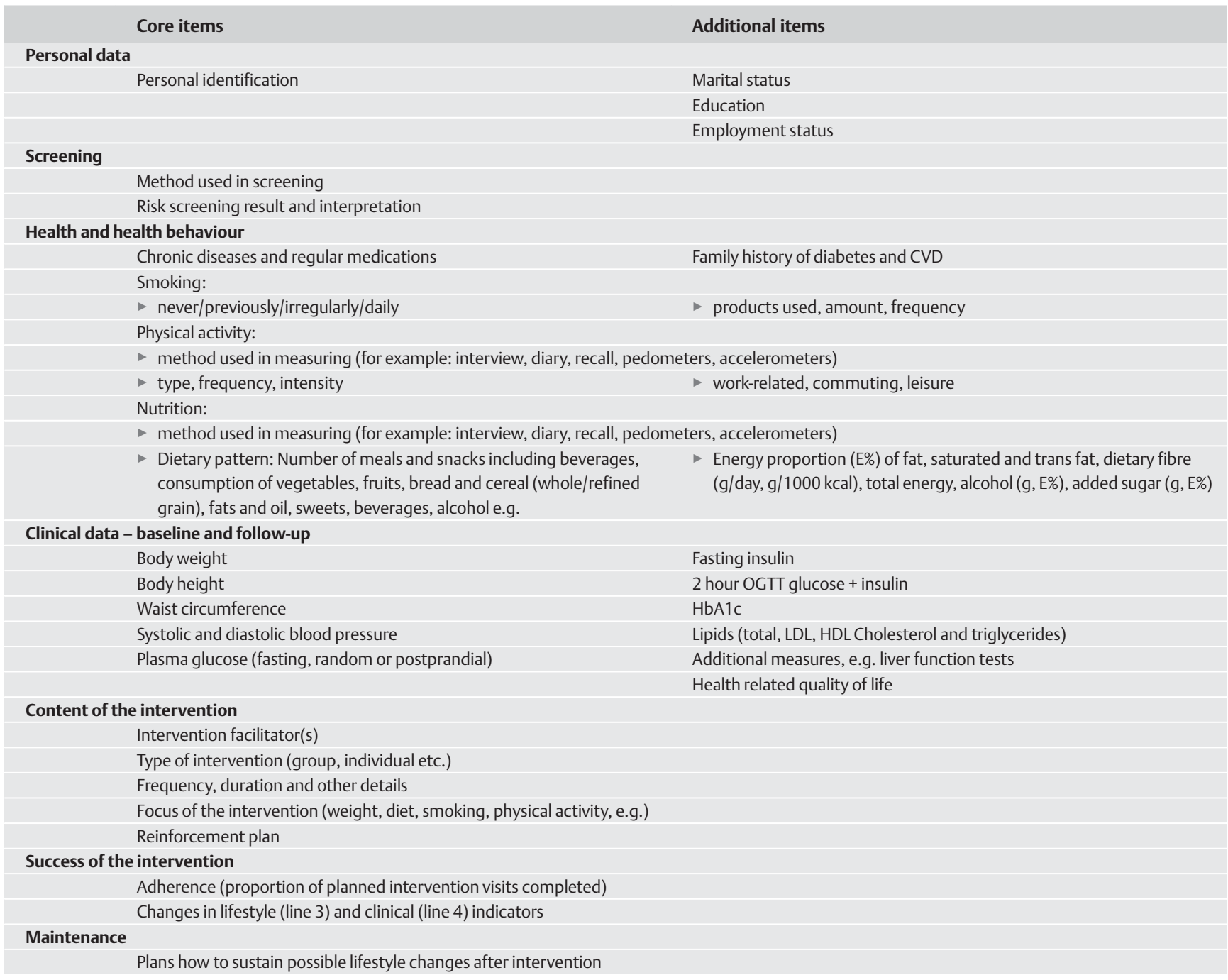

Image Evaluation and Quality Assurance Data Collection

$\nabla$

See $\odot$ Table 9 .

\section{The Development of the IMAGE Toolkit for Diabetes Prevention \\ $\nabla$}

Aim

The Grant Agreement between the Public Health Executive Agency (PHEA; now European Agency for Health and Consumers, EAHC) and the IMAGE Group 2006309-IMAGE stated that the primary objective was "The development of practice-oriented European guidelines for the prevention of type 2 diabetes (T2DM)". To implement this specific objective, a working group 4(a) was established. The group collected the latest evidence and summarised their findings in "A European Evidence-Based Guideline for the Prevention of Type 2 Diabetes - IMAGE-Guideline for diabetes prevention". A second working group, 4(b), was also set up with the aim to create a credible, simplistic, concise, clear, pragmatic, accessible document with a positive message about health promotion ("a toolkit") with step-by-step tips on how to initiate and manage a lifestyle intervention to prevent type 2 diabetes.

\section{Members of the working group}

The members of the working group were selected based on their practical and/or scientific experience in the field of diabetes prevention and were suggested and invited by IMAGE steering group members. Further, the members represent different professional backgrounds which are relevant to diabetes prevention, including health psychology, physical activity, nutrition, health promotion, diabetology, health services provision, health policy development and service user representation.

\section{Group meetings}

The IMAGE Toolkit group had two meetings: the first in Frankfurt, Germany 25-26 May 2009, and the second in Helsinki, Finland 24-25 August 2009. Work was assigned to group members during the meetings and the majority of work was completed between and after meetings. Communications were via e-mails and telephone calls. 


\section{Target group}

The target group for the Toolkit was anyone with an interest in establishing a programme to prevent type 2 diabetes. This includes service providers in the field of health care and health promotion but also politicians and policy-makers. The Toolkit aimed to provide a good balance between clear, accurate information and practical guidance. It is not intended to be a comprehensive source of information, but preferably to be used alongside the "IMAGE Guideline for diabetes prevention" and the associated training curriculum (please see www.image-project.eu). Intervention delivery staff is assumed to have basic knowledge about e.g. diet and physical activity as well as their health effects and supporting behaviour change. Finally, the Toolkit is not designed to be used as intervention materials to be delivered directly to those participating in prevention interventions, although it does contain some examples of information sheets and materials which might be used with participants (for further information, please see www.image-project.eu).

\section{Content of the toolkit}

The Toolkit starts with an executive summary including the rationale for diabetes prevention. It is followed by chapters representing the background (type 2 diabetes prevalence, risk factors, consequences, evidence of successful prevention), and giving instructions about the planning and development of prevention programmes and the identification, and recruitment of participants at high risk for T2DM.

One of the core items of the toolkit is the description of what to do and how to do it. Behaviour change is a process which requires individual attention, and effective communication to achieve motivation, self-monitoring, sustained support and other intervention to prevent and manage relapses. This section includes a model of intervention including empowerment and patient-centred messages. It is followed by key messages on behaviour (including physical activity and diet) that are important in prevention of diabetes, and practical advice for patient-centred counselling. The focus is on long-term, sustainable lifestyle changes. Of note, detailed instructions about how to achieve weight reduction were left out because local and national guidelines as well as other information are available elsewhere.
Finally, a brief guide for evaluation and quality assurance in reference to the "IMAGE quality indicators" is included. This section is followed by a consideration of possible risks and adverse effects. The IMAGE toolkit main text ends with a positive mission statement, emphasizing what can be achieved if we work together. The appendix of the toolkit gives the reader a set of easy-to-use tools including a checklist for prevention programme development, templates for goal-setting and for food and physical activity diaries, an example of a risk screening questionnaire (the FINDRISC questionnaire) and a template for evaluation and quality assurance data collection.

\section{Creation of the toolkit}

The first draft of the toolkit was collated in July 2009. The draft was sent to all members of the toolkit working group for comments and suggestions. During the Helsinki meeting in August 2009 , the content and structure of the document was addressed page-by-page.

A revised version was prepared in September 2009 and sent to all IMAGE work package leaders for comments and suggestions. In mid-October, the toolkit was sent to the entire IMAGE study group for comments. The IMAGE final convention took place in Lisbon, 29-31 October 2009. During this meeting, the toolkit was presented to the whole IMAGE study group followed by a general discussion regarding, e.g. focus, content and wording. All participants were invited to further comment in writing on the version provided at the final convention. Based on the comments and suggestions from the IMAGE group, a pre-final version was prepared by JL, AN and PS in Dresden in December 2009.

The final revision phase was conducted via the global "Who is active in diabetes prevention" network (www.activeindiabetesprevention.com) between December 2009 and January 2010, by inviting all 2900 members of the Network (who represent a wide range of stakeholders in diabetes prevention from academics to service providers in over 130 countries) to comment on the toolkit.

By the end of January 2010, 13 members of the Network and several members of the IMAGE study group had submitted further comments about the toolkit. These were collated and sent to the chapter authors to give their response. Final revisions to the toolkit were made by JL, AN, PS and JT in February 2010. 